\title{
Simultaneous Determination of Canagliflozin and Metformin in Human Plasma by LC-MS/MS Assay and its Application to a Human Pharmacokinetic Study
}

\author{
Muralikrishna Ramisetti ${ }^{1}$, Lakshmana Rao Atmakuri ${ }^{2, *}$, Basaveswara Rao Mandava Venkata ${ }^{3}$, \\ Vinayender Adireddy ${ }^{4}$
}

${ }^{1}$ Faculty of Pharmacy, Krishna University, Machilipatnam, Andhra Pradesh, INDIA.

${ }^{2}$ V. V. Institute of Pharmaceutical Sciences, Gudlavalleru, Andhra Pradesh, INDIA.

${ }^{3}$ Department of Chemistry, Krishna University, Machilipatnam, Andhra Pradesh, INDIA.

${ }^{4}$ PCR Laboratories, Ramanthapur, Hyderabad, Telangana, INDIA.

\begin{abstract}
Objective: The main objective of this work was to develop a simple, rapid and sensitive liquid chromatography/tandem mass spectrometry (LC-MS/MS) method for the simultaneous quantification of Canagliflozin and Metformin. Methods: Deuterated compounds of respective drugs were used an internal standard. Sample extraction was carried out using a simple Protein Precipitation (PP) technique. $\mathrm{A} \mathrm{C}_{18}$ column with an isocratic mobile phase composed of $5 \mathrm{mM}$ ammonium acetate with $0.01 \%$ formic acid and methanol were used for chromatographic separation. Results: The method was validated in the linearity range of $10.00-6028.00 \mathrm{ng} / \mathrm{mL}$ for Canagliflozin and $10.00-$ $3027.00 \mathrm{ng} / \mathrm{mL}$ for Metformin. The precision and accuracy results over five concentration levels in five different batches were well within the acceptance limits. A variety of stability tests were executed in plasma and in neat samples are comply with the FDA guidelines. Conclusion: The proposed assay method is simple, rapid and sensitive for the simultaneous determination of Canagliflozin and Metformin in human plasma. This method was successfully used to quantitate the in vivo plasma concentrations obtained from a pharmacokinetic study.
\end{abstract}

Key words: Canagliflozin, Metformin, Human Plasma, LC-MS/MS, Method Validation, Pharmacokinetics.

\section{INTRODUCTION}

Type 2 Diabetes (T2DM) is a complex metabolic disorder characterized by impaired insulin secretion and impaired insulin action. ${ }^{1}$ Chronic hyperglycaemia and uncontrolled glucose levels results T2DM progression and enhanced risk of complications and mortality. To achieve optimal glucose, control it is often necessary to rely on combination therapy of multiple drugs or insulin. ${ }^{2}$

Canagliflozin, a Sodium-glucose co-transporter 2 (SGLT2) inhibitor used to manage T2DM. By inhibiting SGLT2, Canagliflozin reduces reabsorption of filtered glucose and lowers the renal threshold for glucose
$\left(\mathrm{RT}_{\mathrm{G}}\right)$ and thereby increases urinary glucose excretion. ${ }^{3}$ It is used as an adjunct to diet and exercise. ${ }^{3-5}$ Metformin is one of the most commonly prescribed drug worldwide for T2DM therapy. Metformin lowers both basal and Postprandial Plasma Glucose (PPG) and improving the glucose uptake and utilization. Metformin has additional benefits like weight reduction, lowering lipid levels and prevention of some vascular complications. $^{6-8}$

Metformin is a first-line therapy for patients with T2DM. Though, many patients do not achieve effective glycemic control with Met-
Submission Date: 12-03-2019; Revision Date: 26-04-2019 Accepted Date: 02-07-2019

DOI: 10.5530/ijper.53.3s.107 Correspondence: Dr. A. Lakshmana Rao, Principal, V. V. Institute of Pharmaceutical Sciences, Gudlavalleru- 521 356, Andhra Pradesh, INDIA.

Phone: +91-9848779133

E-mail: dralrao@gmail.com

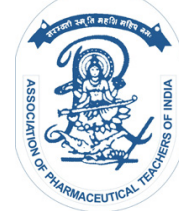

www.ijper.org 
formin alone and require subsequent combination therapy with other antihyperglycemic agents. The American Association for Clinical Endocrinologists algorithm for the treatment of T2DM recommends Metformin plus SGLT2 inhibitor as the first oral combination in patients with $\mathrm{HbA} 1 \mathrm{c} \geq 7.5 \%$ for a better glycemic control. Canagliflozin in combination with Metformin provided more glycemic control than monotherapy. ${ }^{9,10}$ INVOKAMET $^{\mathrm{TM}}$ (Janssen Pharmaceuticals, Inc.) a combination of Canagliflozin and Metformin is available in the market with variable dosing.

Many analytical methods were reported in literature for the determination of Canagliflozin ${ }^{5,11}$ and Metformin ${ }^{12-22}$ individually or with some other drugs in biological samples. These methods are only suitable for quantitation of one drug in biological samples selectively and sensitively may not be suitable for simultaneous quantification Canagliflozin and Metformin. Analysis of Canagliflozin and Metformin in a single run is challenge due to their different physiochemical properties. To address the pharmacokinetics of the new combined formulation, a sensitive and specific method that allows simultaneous measurement of Canagliflozin and Metformin in human plasma is needed. Recently, Shah et al. $2018^{23}$ published a LC-MS/MS method for the simultaneous determination of Canagliflozin and Metformin in plasma samples. Though the method is sensitive, the total run time was more than 4 min and complex with the use of ion pairing agents during sample preparation.

In the present work, the authors developed a simple, sensitive and selective LC-MS/MS assay method for the determination of Canagliflozin and Metformin in human plasma using isotope labelled internal standards Canagliflozin d4 (IS1) and Metformin d6 (IS2), respectively. These internal standards minimize the matrix effect related problems and variability in recovery between analyte and the IS. The method requires only $100 \mu \mathrm{L}$ human plasma for simple and one step Protein Precipitation (PP) technique demonstrates excellent performance in terms of ruggedness with a sample cut off time $2.5 \mathrm{~min}$ for simultaneous quantification of Canagliflozin and Metformin. The validated method was successfully applied to a human pharmacokinetic study.

\section{MATERIALS AND METHODS}

\section{Standards and chemicals}

Reference samples of Canagliflozin (99.96\%), Metformin hydrochloride (100.10\%), Canagliflozin d4 (97.55\%) and Metformin d6 hydrochloride (99.88\%) were obtained from Clearsynth Labs Limited, India. LC-MS/MS grade water was prepared from inhouse water purification system (Millipore, Bangalore, India) and blank plasma obtained from blood bank (Deccan's labs, Hyderabad, India). Formic acid and ammonium acetate were purchased from Merck Ltd (Mumbai, India). Similarly, high purity solvents of acetonitrile and methanol was purchased from J.T Baker (Phillipsburg, USA).

\section{LC-MS/MS instrument and conditions}

A triple quadrupole API-4000 mass spectrometer (AB Sciex, Foster City, CA, USA) coupled with HPLC (Shimadzu Corporations, Kyoto, Japan) was used for the present study. The processed samples were chromatographed on a Hypersil BDS, $C_{18}(100 \times 4.6 \mathrm{~mm}, 5 \mu \mathrm{m})$ column using an isocratic mobile phase composed of $5 \mathrm{mM}$ ammonium acetate with $0.01 \%$ formic acid and methanol $(15: 85, \mathrm{v} / \mathrm{v})$. The flow rate was set at $1.0 \mathrm{~mL} / \mathrm{min}$ and the injection volume was $15 \mu \mathrm{L}$. The optimized mass spectrometric conditions are summarized in the Table 1.

\section{Preparation of spiked plasma samples}

All the stock solutions were prepared in methanol, separately and further dilutions were prepared in 40:60, $\mathrm{v} / \mathrm{v}$ of water and acetonitrile (diluent). Stock solutions were stored in refrigerator at $2-8^{\circ} \mathrm{C}$ for 45 days. Calibration standards and quality control samples were prepared from two independent weighing of the respective standards. Calibrates were prepared at concentrations of 10.27, 20.54, 102.68, 302.01, 604.01, 1208.03, 2416.05, 3616.84, 4822.45 and $6028.07 \mathrm{ng} / \mathrm{mL}$ for Canagliflozin and 10.03, 20.06, 40.11, 80.22, 151.36, 302.73, 605.46, 1210.91, 2421.82 and $3027.28 \mathrm{ng} / \mathrm{mL}$ for Metformin. Similarly, controls were prepared at five different concentration levels of 10.36 and 10.10 (lower limit of quantification, LLOQ), 30.46 and 30.14 (low quality control, LQC), 906.45 and 307.51 (middle quality control, MQC-1), 2713.93 and 1464.36 (MQC-2) and 4523.21 and 2361.86 (high quality control, HQC) ng/mL for Canagliflozin and Metformin, respectively. Plasma samples were stored at $-70 \pm 10^{\circ} \mathrm{C}$. The working solution for Canagliflozin d4 $(30 \mu \mathrm{g} / \mathrm{mL})$ and Metformin d4 $(15 \mu \mathrm{g} / \mathrm{mL})$ was also prepared in diluent.

\section{Sample preparation procedure}

The frozen samples were thawed at room temperature and vortexed to ensure complete mixing of the contents. An aliquot $100 \mu \mathrm{L}$ of plasma sample was pipetted into prelabelled $5 \mathrm{~mL}$ polypropylene tubes and $15 \mu \mathrm{L}$ of internal standard dilution (a combined dilution of $30 \mu \mathrm{g} / \mathrm{mL}$ and $15 \mu \mathrm{g} / \mathrm{mL}$ of Canagliflozin $\mathrm{d} 4$ and Metformin d4, respectively) was added to it. After vortexing for $15 \mathrm{sec}, 3 \mathrm{~mL}$ of acetonitrile was added to each sample and vortexed for $30 \mathrm{sec}$, then centrifuged at $4000 \mathrm{rpm}$ for $10 \mathrm{~min}$ at $4^{\circ} \mathrm{C} .2 \mathrm{~mL}$ of supernatant layer was transferred to prelabelled glass test tubes and 


\begin{tabular}{|c|c|c|c|c|}
\hline \multirow{2}{*}{ Table 1: Tandem mass-spectrometer main working parameters. } \\
\cline { 2 - 5 } & \multicolumn{4}{|c|}{ Analyte } \\
\cline { 2 - 5 } & $\begin{array}{c}\text { Canagliflozin } \\
\text { Parameter }\end{array}$ & $\begin{array}{c}\text { IS1 } \\
\text { (M+NH4) })^{+}\end{array}$ & Metformin & IS2 \\
\hline Mode of analysis & Positive & Positive & Positive & Positive \\
\hline Ion transition, $\mathrm{m} / \mathrm{z}$ & $462.2 / 267.1$ & $466.0 / 267.1$ & $130.1 / 71.1$ & $136.1 / 77.1$ \\
\hline Source temperature, ${ }^{\circ} \mathrm{C}$ & 500 & 500 & 500 & 500 \\
\hline Dwell time, msec & 100 & 100 & 100 & 100 \\
\hline GS1, psi & 45 & 45 & 45 & 45 \\
\hline GS2, psi & 45 & 45 & 45 & 45 \\
\hline Curtain gas, psi & 35 & 35 & 35 & 35 \\
\hline Collision gas, psi & 6 & 6 & 6 & 6 \\
\hline Ion spray voltage, V & 5000 & 5000 & 5000 & 5000 \\
\hline Entrance potential, V & 10 & 10 & 10 & 10 \\
\hline Declustering potential, V & 60 & 60 & 50 & 50 \\
\hline Collision energy, V & 26 & 26 & 32 & 32 \\
\hline Collision cell exit potential, V & 10 & 10 & 6 & 6 \\
\hline Resolution & Unit & Unit & Unit & Unit \\
\hline
\end{tabular}

evaporated to dryness at $45^{\circ} \mathrm{C}$ under gentle stream of nitrogen. The dried extract was reconstituted with $500 \mu \mathrm{L}$ of the mobile phase and injected.

\section{Method validation}

The following validation tests were conducted as per the recent U.S Food and Drug Administration (US FDA) ${ }^{24}$ guidelines: carryover test, system suitability, matrix effect, selectivity, precision and accuracy, linearity, long run evaluation, dilution integrity, ruggedness and stability studies.

\section{Pharmacokinetic study design}

A pharmacokinetic study was performed in healthy male subjects $(n=6)$. Informed consent was obtained from each subject. All the subjects were selected based on their body-mass index (BMI) of $\geq 18.5 \mathrm{~kg} / \mathrm{m}^{2}$ and $\leq 24.9 \mathrm{~kg} / \mathrm{m}^{2}$, with body weight not less than $50 \mathrm{~kg}$. Medical history of the subjects was considered before inclusion in study. The subjects were tested for clinical tests such as hepatic and renal profile, blood glucose levels, whole blood count and screened for infectious diseases like HIV 1 and 2, HbsAg (Hepatitis-B) and HCV (Hepatitis-C). Blood samples $(4 \mathrm{~mL})$ were collected following oral administration of $150 \mathrm{mg}$ tablet of Canagliflozin and $500 \mathrm{mg}$ tablet of Metformin hydrochloride at pre-dose and $0.25,0.5,0.75,1,1.25$, $1.5,1.75,2,2.25,2.5,2.75,3,3.25,3.5,3.75,4,4.5,5$, $6,8,10,12,16,24,36,48$ and $72 \mathrm{~h}$ in K2-EDTA vacutainer collection tubes (BD, Franklin, NJ, USA). The blood samples were centrifuged at $4000 \mathrm{rpm}$ for $10 \mathrm{~min}$ and the plasma was collected. The plasma samples were stored at $-70 \pm 10^{\circ} \mathrm{C}$ till their analysis. Plasma concentration-time profile of each analyte was analyzed by non-compartmental method using WinNonlin Version 5.1.

\section{RESULTS AND DISCUSSION}

\section{Method development}

The aim of the present study was to develop and validate a rapid and sensitive LC-MS/MS method for the simultaneous determination of Canagliflozin and Metformin in human plasma. Mass parameters were tuned in both positive and negative ionization modes for the analytes. The response obtained for Canagliflozin was low and not enough to quantify in positive and negative mode. Hence, as described in the earlier report ${ }^{5}$ intensity of ammonium adduct $\left(\mathrm{M}+\mathrm{NH}_{4}\right)^{+}$of Canagliflozin was monitored. Data acquisition was performed in the Multiple Reaction Monitoring (MRM) mode to obtain better selectivity. The source dependent parameters such as curtain gas, collision gas, GS1 and GS2 were suitably altered to get satisfactory and reproducible response. Similarly, compound dependent parameters namely Collision Energy (CE), Declustering Potential (DP) and collision cell exit potential (CXP) were altered to get most intense and consistent product ion Q3 MS spectra of analytes. The positive ion spray mass spectrum shown a protonated molecular species by monitoring the transition pairs of $\mathrm{m} / \mathrm{z} 462$ precursor ion to the $\mathrm{m} / \mathrm{z} 267$ for Canagliflozin, $\mathrm{m} / \mathrm{z} 130$ precursor ion to the $\mathrm{m} / \mathrm{z} 71$ product ion for the Metformin, $\mathrm{m} / \mathrm{z} 466$ precursor ion to the $\mathrm{m} / \mathrm{z} 267$ product ion for 
Canagliflozin- $\mathrm{d} 4$ and $\mathrm{m} / \mathrm{z} 136$ precursor ion to the $\mathrm{m} / \mathrm{z}$ 77 product ion for Metformin-d4. Data integration was performed with Analyst Software ${ }^{\mathrm{TM}}$ (version 1.4.2).

The important chromatographic conditions such as mobile phase composition, analytical column type and flow rate were carefully monitored to obtain the good resolution from the endogenous components and better peak shape. The widely used buffers in mass spectrometry analysis are ammonium formate and ammonium acetate and acid modifiers are formic acid and acetic acid due to their volatility and ease of evaporation. Similarly, widely used organic solvents are acetonitrile and methanol. Hence, the mobile phase composition was elevated with acetonitrile and methanol by varying its proportion with above mentioned volatile buffers at different strengths. Additionally, a variety of analytical columns (Hypersil BDS, Kromasil $\mathrm{C}_{8}$; Zodiac $\mathrm{C}_{18}$, Zorbax $\mathrm{SB} \mathrm{C}_{18}$, Zorbax XDB-phenyl; Zorbax SB C Hypurity Adavance, Inertsil ODS, etc) were tested for better selectivity and sensitivity of an assay.

An isocratic mobile phase composition with acetonitrile/ methanol and ammonium formate (5 and $10 \mathrm{mM}) /$ formic acid buffer $(0.01$ and $0.03 \%)$ was tested at different flow rates $(0.5,0.7$ and $1.0 \mathrm{~mL} / \mathrm{min})$. But area response was not reproducible with bad peak shape especially for metformin. Therefore, ammonium acetate was tested in combination with methanol and acetonitrile using above mentioned analytical columns. A combination of ammonium acetate with methanol gave better peak shape and response compared to above listed solvents. Analytes response was significantly increased by adding $0.01 \%$ formic acid to ammonium acetate buffer. Among the various chromatographic columns tested for their suitability Hypersil BDS C $18(100 * 4.6 \mathrm{~mm}, 5 \mu \mathrm{m})$ column gave better peak shape for Canagliflozin and Metformin with retention time of 1.5 and $1.8 \mathrm{~min}$, respectively. The shortest run time of $2.5 \mathrm{~min}$ was achieved with flow rate of $1.0 \mathrm{~mL} / \mathrm{min}$.

The quality of sample preparation significantly impacts the mass spectrometry results. Presence of endogenous compounds in the extracted sample decreases the mass spectrometric performance. SPE is an efficient extraction method to remove the endogenous components from biological samples. But it requires many stringent method development protocols, equipment's and expensive. We aimed to develop a simple and efficient extraction method, PP was tested. PP with acetonitrile and methanol was tested. Highest recoveries for Canagliflozin and Metformin was obtained with acetonitrile compared to methanol. Deuterated standards of Canagliflozin and Metformin were used as internal standards to increase the precision and to decrease the variability in recovery.

\section{Carryover test, selectivity, sensitivity and matrix effect}

A mixture of methanol and acetonitrile $(50: 50, \mathrm{v} / \mathrm{v})$ was used as rinsing solution. No noticeable carryover was observed in successive blank sample runs after injection of ULOQ sample of both the analytes. A system suitability test was performed every day before start of analysis and the precision (\%CV) for response ratio of both the analytes were less than $1.5 \%$. All the blank plasma lots tested were free from significant interfere at the retention time of Canagliflozin and Metformin. The representative extracted blank plasma chromatograms were shown in Figure 1. Similarly, no significant interference was observed from the respective internal standards at the MRM channels of the analytes. Limit of Quantitation (LOQ) for Canagliflozin and Metformin was set at $10.27 \mathrm{ng} / \mathrm{mL}$ and $10.03 \mathrm{ng} / \mathrm{mL}$, respectively (Figure 2). The precision (\% CV) and accuracy at this concentration was 1.75 and $103.10 \%$ and 3.23 and $93.61 \%$ for Canagliflozin and Metformin, respectively. Also, at LOQ concentration, the signalto-noise ratio for Canagliflozin and Metformin were above 1:10. The average IS normalized matrix factor value calculated at LQC and HQC levels was found to be 1.01 and 1.01 for Canagliflozin and 0.99 and 1.00 for Metformin, which shows negligible ion suppression or enhancement. Similarly, the precision $(\% \mathrm{CV})$ at LQC and HQC levels was found to be 2.08 and $0.37 \%$ for Canagliflozin and 2.64 and $0.75 \%$ for Metformin.

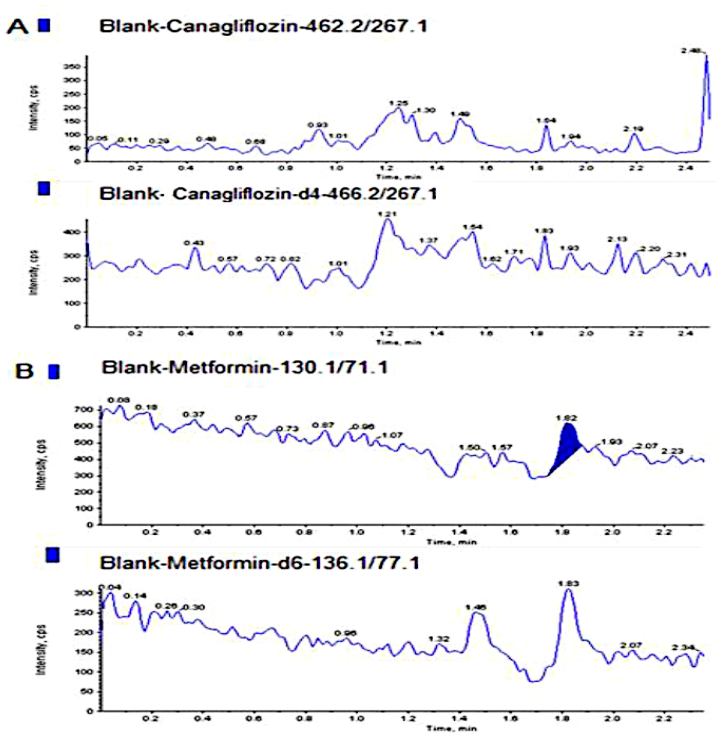

Figure 1: Typical MRM chromatogram of (A) canagliflozin and its IS (B) metformin and its IS in human blank plasma. 


\section{Linearity, precision and accuracy}

A total of five calibration curves containing five QC concentration levels covering the whole linearity range were run in three different days. Of the above, one calibration curve with QC samples were analyzed using set of reagents and with different analyst to establish the method ruggedness. The calibration curve was found to be linear over the concentration range of 10.27-6028.07 ng/mL for Canagliflozin and 10.03$3027.28 \mathrm{ng} / \mathrm{mL}$ for Metformin. The mean correlation

\begin{tabular}{|c|c|c|c|c|c|c|c|}
\hline \multicolumn{2}{|c|}{ QC } & \multicolumn{3}{|c|}{$\begin{array}{c}\text { Intra-day precision and accuracy } \\
(n=12 ; 6 \text { from each batch) }\end{array}$} & \multicolumn{3}{|c|}{$\begin{array}{c}\text { Inter-day precision and accuracy } \\
\text { ( } n=30 ; 6 \text { from each batch) }\end{array}$} \\
\hline Analyte & $\begin{array}{l}\text { Concentration } \\
\text { spiked }(\mathrm{ng} / \mathrm{mL})\end{array}$ & $\begin{array}{c}\text { Concentration } \\
\text { found (mean; } \\
n g / m L)\end{array}$ & $\begin{array}{l}\text { Precision } \\
\quad(\%)\end{array}$ & Accuracy (\%) & $\begin{array}{c}\text { Concentration } \\
\text { found (mean; } \\
n g / m L)\end{array}$ & $\begin{array}{l}\text { Precision } \\
(\%)\end{array}$ & $\begin{array}{l}\text { Accuracy } \\
(\%)\end{array}$ \\
\hline Canagliflozin & $\begin{array}{c}10.4 \\
30.5 \\
906 \\
2714 \\
4523\end{array}$ & $\begin{array}{c}10.3 \pm 0.37 \\
29.6 \pm 0.62 \\
964 \pm 7.56 \\
2581 \pm 16.2 \\
4663 \pm 25.3\end{array}$ & $\begin{array}{l}3.56 \\
2.11 \\
0.78 \\
0.63 \\
0.54\end{array}$ & $\begin{array}{c}99.8 \\
97.0 \\
106 \\
95.1 \\
103\end{array}$ & $\begin{array}{c}10.0 \pm 0.69 \\
29.1 \pm 1.00 \\
970 \pm 8.19 \\
2602 \pm 26.4 \\
4814 \pm 170\end{array}$ & $\begin{array}{l}6.88 \\
3.45 \\
0.84 \\
1.01 \\
3.53\end{array}$ & $\begin{array}{r}96.6 \\
95.9 \\
107 \\
95.9 \\
106\end{array}$ \\
\hline Metformin & \begin{tabular}{c|}
10.1 \\
30.1 \\
308 \\
1464 \\
2362
\end{tabular} & $\begin{array}{c}10.6 \pm 0.79 \\
31.1 \pm 0.97 \\
325 \pm 11.5 \\
1522 \pm 68.6 \\
2312 \pm 100\end{array}$ & $\begin{array}{l}7.42 \\
3.12 \\
3.55 \\
4.51 \\
4.33\end{array}$ & $\begin{array}{l}105 \\
103 \\
106 \\
104 \\
97.9\end{array}$ & $\begin{array}{c}10.6 \pm 0.72 \\
31.3 \pm 0.84 \\
324 \pm 10.4 \\
1467 \pm 95.4 \\
2262 \pm 94.9\end{array}$ & $\begin{array}{l}6.78 \\
2.69 \\
3.20 \\
6.51 \\
4.19\end{array}$ & $\begin{array}{l}105 \\
104 \\
105 \\
100 \\
95.8\end{array}$ \\
\hline
\end{tabular}

\begin{tabular}{|c|c|c|c|c|c|}
\hline Analyte & Stability test & $\begin{array}{c}\text { QC (spiked } \\
\text { concentration }(\mathrm{ng} / \mathrm{mL})\end{array}$ & Mean \pm SD $(\mathrm{ng} / \mathrm{mL})$ & Precision (\%) & $\begin{array}{c}\text { Accuracy/ } \\
\text { Stability (\%) }\end{array}$ \\
\hline \multirow{10}{*}{ Canagliflozin } & $\begin{array}{c}\text { Benchtop at } 20^{\circ} \mathrm{C} \\
(20 \mathrm{hr})\end{array}$ & 30.5 & $28.5 \pm 0.88$ & 3.07 & 93.7 \\
\hline & & 4523 & $4723 \pm 34.8$ & 0.74 & 104 \\
\hline & $\begin{array}{c}\text { Freeze-thaw }-70^{\circ} \mathrm{C} \\
\text { (4 cycles) }\end{array}$ & 30.5 & $29.2 \pm 0.47$ & 1.62 & 95.8 \\
\hline & & 4523 & $4755 \pm 55.0$ & 1.16 & 105 \\
\hline & Autosampler $5^{\circ} \mathrm{C}(55 \mathrm{hr})$ & 30.5 & $29.5 \pm 0.29$ & 0.99 & 96.8 \\
\hline & & 4523 & $4782 \pm 57.5$ & 1.20 & 106 \\
\hline & $\begin{array}{c}\text { Wet extract at } 2-8^{\circ} \mathrm{C} \\
(50 \mathrm{hr})\end{array}$ & 30.5 & $30.4 \pm 1.74$ & 5.73 & 99.8 \\
\hline & & 4523 & $4705 \pm 35.9$ & 0.76 & 104 \\
\hline & $\begin{array}{c}\text { Long-term at }-70^{\circ} \mathrm{C} \\
\text { (75 days) }\end{array}$ & 30.5 & $29.8 \pm 1.25$ & 4.20 & 97.7 \\
\hline & & 4523 & $4642 \pm 76.6$ & 1.65 & 103 \\
\hline \multirow{10}{*}{ Metformin } & $\begin{array}{c}\text { Benchtop at } 20^{\circ} \mathrm{C} \\
(20 \mathrm{hr})\end{array}$ & 30.1 & $31.3 \pm 1.21$ & 3.86 & 104 \\
\hline & & 2362 & $2319 \pm 36.9$ & 1.59 & 98.2 \\
\hline & $\begin{array}{c}\text { Freeze-thaw }-70^{\circ} \mathrm{C} \\
\text { (4 cycles) }\end{array}$ & 30.1 & $30.6 \pm 1.38$ & 4.53 & 101 \\
\hline & & 2362 & $2325 \pm 31.6$ & 1.36 & 98.4 \\
\hline & Autosampler $5^{\circ} \mathrm{C}(55 \mathrm{hr})$ & 30.1 & $30.7 \pm 0.61$ & 1.99 & 102 \\
\hline & & 2362 & $2309 \pm 20.5$ & 0.89 & 97.8 \\
\hline & $\begin{array}{l}\text { Wet extract at } 2-8^{\circ} \mathrm{C} \\
(50 \mathrm{hr})\end{array}$ & 30.1 & $31.7 \pm 0.47$ & 1.49 & 105 \\
\hline & & 2362 & $2289 \pm 30.2$ & 1.32 & 96.9 \\
\hline & $\begin{array}{c}\text { Long-term at }-70^{\circ} \mathrm{C} \\
\text { (75 days) }\end{array}$ & 30.1 & $32.0 \pm 0.72$ & 2.24 & 106 \\
\hline & & 2362 & $2297 \pm 20.8$ & 0.90 & 97.2 \\
\hline
\end{tabular}




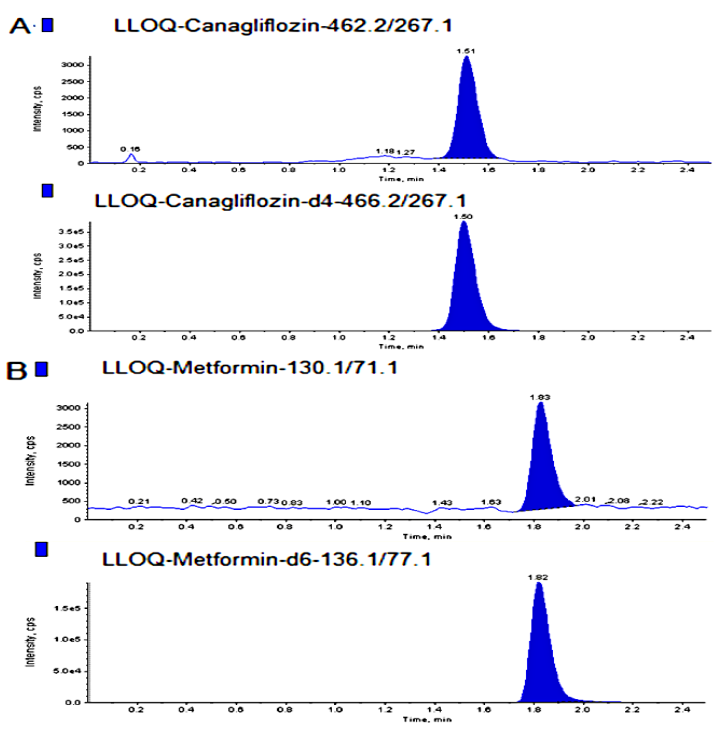

Figure 2: Typical MRM chromatogram of (A) canagliflozin and its IS (B) metformin and its IS in a LLOQ sample.

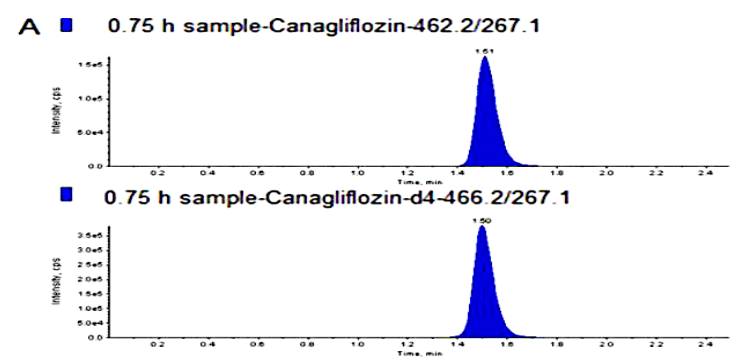

B

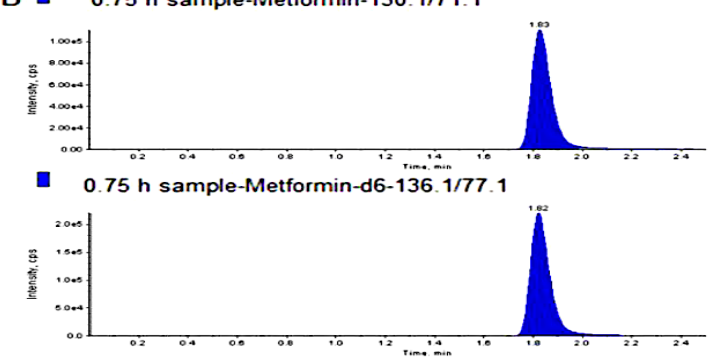

Figure 3: Typical MRM chromatogram of a $0.75 \mathrm{~h}$ plasma sample showing (A) canagliflozin and (B) metformin peak along with the respective IS obtained following oral administration of $150 / 500 \mathrm{mg}$ of canagliflozin and metformin tablet to a healthy volunteer.

Table 4: Pharmacokinetic parameters of canagliflozin (150 $\mathrm{mg})$ and metformin (500 $\mathrm{mg})(n=6$, Mean \pm SD).

\begin{tabular}{|c|c|c|}
\hline Parameter & Canagliflozin & Metformin \\
\hline $\mathrm{C}_{\max }(\mathrm{ng} / \mathrm{mL})$ & $1436 \pm 165$ & $1105 \pm 127$ \\
\hline $\mathrm{T}_{\max }(\mathrm{h})$ & $3.88 \pm 2.28$ & $2.54 \pm 0.93$ \\
\hline $\mathrm{AUC}_{0-\mathrm{t}}(\mathrm{ng} \mathrm{h} / \mathrm{mL})$ & $13132 \pm 2674$ & $8968 \pm 1832$ \\
\hline $\mathrm{AUC}_{0-\text { inf }}(\mathrm{ng} \mathrm{h} / \mathrm{mL})$ & $13528 \pm 2899$ & $9156 \pm 1837$ \\
\hline $\mathrm{t}_{1 / 2}(\mathrm{~h})$ & $8.98 \pm 1.18$ & $5.63 \pm 3.46$ \\
\hline $\mathrm{Kel}\left(\mathrm{h}^{-1}\right)$ & $0.08 \pm 0.01$ & $0.15 \pm 0.05$ \\
\hline
\end{tabular}

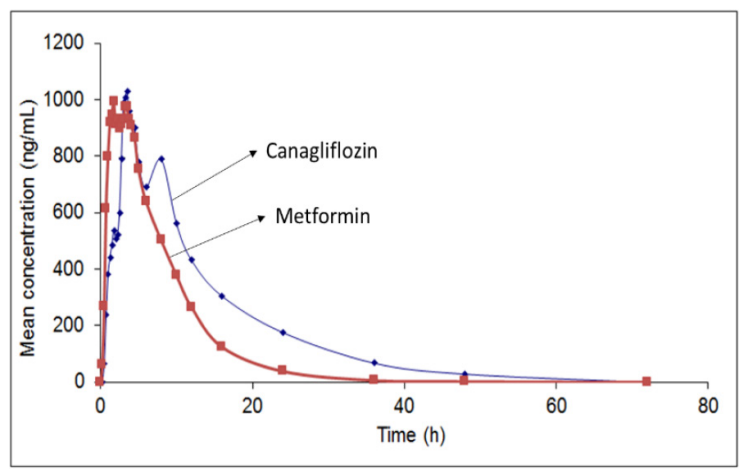

Figure 4: Mean plasma concentration-time profile of canagliflozin $(150 \mathrm{mg})$ and metformin $(500 \mathrm{mg})$ in healthy male subjects $(n=6)$.

coefficient values were $\geq 0.99$ for Canagliflozin and Metformin. After comparing the two weighting models $\left(1 / x\right.$ and $\left.1 / x^{2}\right)$ and a regression equation with a weighting factor of $1 / x^{2}$ was found to establish the best relationship between concentration-detector response.

The intra-day and inter-day precision and accuracy results are presented in Table 2. The precision results in both the occasions for Canagliflozin and Metformin was less than $15 \%$ and accuracy was $100 \pm 15 \%$ of the actual values at LQC, MQC-1, MQC-2 and HQC level, whereas at LLOQ QC level the precision was less than $20 \%$ and accuracy was $100 \pm 20 \%$.

\section{Recovery and dilution integrity}

The simple PP with acetonitrile gives highest recovery for Canagliflozin and Metformin. The mean extraction recovery with precision range for Canagliflozin, Metformin, IS1 and IS2 were $81.72 \%(0.56-4.09 \%)$, $88.77 \% \quad(1.41-5.52 \%), \quad 90.55 \% \quad(4.58-5.44 \%)$ and $90.38 \%$ (3.07-7.61\%), respectively. The dilution integrity experiment was conducted to increase the upper limit of quantitation if needed. A set of samples were prepared by spiking (about 3.3 times of ULOQ) Canagliflozin and Metformin at concentration of $20103.16 \mathrm{ng} / \mathrm{mL}$ and $10301.54 \mathrm{ng} / \mathrm{mL}$ and stored at $-70^{\circ} \mathrm{C}$ overnight prior to analysis. Six aliquots were diluted to two folds and four folds dilution with screened human blank plasma. The results of two and four-fold dilutions for both the analytes were well within the limits.

\section{Stability studies}

In the different stability experiments carried out viz. bench top stability $(20 \mathrm{hr})$, auto-sampler stability at $5^{\circ} \mathrm{C}$ $(55 \mathrm{~h})$ repeated freeze-thaw cycles (4 cycles), postprocessing sample stability $\left(50 \mathrm{~h}\right.$ at $\left.2-8^{\circ} \mathrm{C}\right)$ Re-injection reproducibility $(45 \mathrm{hr})$ and long term stability at $-70^{\circ} \mathrm{C}$ for 75 days the mean $\%$ nominal values of the analyte 
were found to be within $\pm 15 \%$ of the predicted concentrations for the analyte at their LQC and HQC levels (Table 3). Thus, the results were found to be within the acceptable limits during the entire validation.

\section{Pharmacokinetic results}

The validated method was successfully used to determine the in-vivo sample concentrations of Canagliflozin and Metformin obtained from a pharmacokinetic study. A representative chromatogram resulting from the analysis of $0.75 \mathrm{~h}$ subject plasma sample of Canagliflozin and Metformin is shown in the Figure 3. Similarly, the mean concentration-time profiles of a single oral dosage Canagliflozin (150mg) and Metformin (500mg) after a single oral dosage is shown in Figure 4 and the corresponding pharmacokinetic parameters are listed in Table 4. Pharmacokinetic parameters of the Canagliflozin are dose comparable with the values reported earlier. ${ }^{5}$ Similarly, pharmacokinetics of Metformin were in close proximity to the values reported by earlier researchers. ${ }^{14}$

\section{CONCLUSION}

We have developed a rapid and sensitive LC-MS/MS method for simultaneous quantification of Canagliflozin and Metformin in human plasma using stable labelled isotopes as internal standards. The method was fully validated as per Guidelines for Industry, Bioanalytical Method Validation, U.S. Food and Drug Administration. The method employs simple and one step PP for samples preparation using $100 \mu \mathrm{L}$ of the plasma volume and obtained highest recovery for the analytes. The stability Canagliflozin and Metformin in plasma as well as in processed samples have been extensively evaluated and obtained results were acceptable in all the specified conditions. The method was found to be reliable and reproducible to support a pharmacokinetic and bioequivalence study in healthy volunteers.

\section{ACKNOWLEDGEMENT}

The authors gratefully acknowledge PCR Laboratories, India for providing necessary facilities to carry out this work.

\section{CONFLICT OF INTEREST}

The authors declare no conflict of interests to declare.

\section{ABBREVIATIONS}

LC-MS/MS: Liquid Chromatography-Tandem Mass Spectrometry; US FDA: United States Food and Drug Administration; IS: Internal Standard, LQC: Low Quality Control; MQC: Middle Quality Control; HQC: High Quality Control; ULOQ: Upper Limit of Quantitation; FDC: Fixed Dose Combination.

\section{REFERENCES}

1. Scheen AJ. Pharmacotherapy of 'treatment resistant' type 2 diabetes. Expert Opinion on Pharmacotherapy. 2017;18(5):503-15.

2. Mannino GC, Andreozzi F, Sesti G. Pharmacogenetics of Type 2 Diabetes Mellitus, the route toward tailored medicine. Diabetes Metabolism Research Reviews. 2019;35(3):e3109.

3. Devineni D, Curtin CR, Polidori D, Gutierrez MJ, Murphy J, Rusch S, et al. Pharmacokinetics and pharmacodynamics of Canagliflozin, a sodium glucose co-transporter 2 inhibitor, in subjects with type 2 diabetes mellitus. Journal of Clinical Pharmacology. 2013;53(6):601-10

4. Chen X, Hu P, Vaccaro N, Polidori D, Curtin CR, Stieltjes H, et al. Pharmacokinetics, pharmacodynamics and safety of single-dose Canagliflozin in healthy Chinese subjects. Clinical Therapeutics. 2015;37(7):1483-92.

5. Somarouthu VS, Pilli NR, Bimireddy BPK, Pandiyan PS. A novel and rapid LC-MS/MS assay method for the determination of Canagliflozin in human plasma by solid phase extraction technique and its application to a pharmacokinetic study. Future Journal of Pharmacy and Pharmaceutical Sciences. 2018;4(2):131-8.

6. Gong L, Goswami S, Giacomini KM, Altman RB, Klein TE. Metformin pathways: pharmacokinetics and pharmacodynamics. Pharmacogenet Genomics. 2012;22(11):820-7.

7. Scarpello JH, Howlett HC. Metformin therapy and clinical uses. Diabetes Vascular Disease Research. 2008;5(3):157-67.

8. Viollet B, Guigas B, Sanz Garcia N, Leclerc J, Foretz M, Andreelli F. Cellular and molecular mechanisms of Metformin: An overview. Clinical Science. 2012;122(6):253-70.

9. Davidson JA, Sloan L. Fixed-dose combination of Canagliflozin and Metformin for the treatment of type 2 diabetes: An overview. Advances in Therapy. 2017;34,(1):41-59.

10. Gupta V, Willis M, Johansen P, Nilsson A, Shah M, Mane A, et al. Longterm clinical benefits of Canagliflozin $100 \mathrm{mg}$ versus sulfonylurea in patients with type 2 diabetes mellitus inadequately controlled with Metformin in India. Value in Health Regional Issues. 2018;18:65-73.

11. Kobuchi S, Yano K, Ito Y, Sakaeda T. A validated LC-MS/MS method for the determination of canagliflozin, a Sodium-glucose co-transporter 2 (SGLT-2) inhibitor, in a lower volume of rat plasma: application to pharmacokinetic studies in rats. Biomed Chromatography. 2016;30(10):1549-55.

12. Wang $\mathrm{Y}$, Tang $\mathrm{Y}, \mathrm{Gu} \mathrm{J}$, Fawcett JP, Bai $\mathrm{X}$. Rapid and sensitive liquid chromatography-tandem mass spectrometric method for the quantitation of metformin in human plasma. Journal of Chromatography B. 2004;808(2):215-9.

13. Shah PA, Shrivastav PS, Shah JV, George A. Simultaneous quantitation of metformin and dapagliflozin in human plasma by LC-MS/MS: Application to a pharmacokinetic study. Biomed Chromatography. 2019;33(4):e4453.

14. Polagani SR, Pilli NR, Gajula R, Gandu V. Simultaneous determination of atorvastatin, metformin and glimepiride in human plasma by LC-MS/MS and its application to a human pharmacokinetic study. Journal of Pharmaceutical Analysis. 2013;3(1):9-19.

15. Abbas MB, Mahrouse MA, Fawzy MG. A validated LC-MS/MS method for simultaneous determination of linagliptin and metformin in spiked human plasma coupled with solid phase extraction: Application to a pharmacokinetic study in healthy volunteers. Journal of Pharmaceutical and Biomedical Analysis. 2019;163:153-61.

16. Zhong GP, Bi HC, Zhou S, Chen X, Huang M. Simultaneous determination of metformin and gliclazide in human plasma by liquid chromatography-tandem mass spectrometry: application to a bioequivalence study of two formulations in healthy volunteers. Journal of Mass Spectrometry. 2005;40(11):1462-71.

17. Ding CG, Zhou Z, Ge QH, Zhi XJ, Ma LL. Simultaneous determination of metformin and glipizide in human plasma by liquid chromatography tandem mass spectrometry. Biomed Chromatography. 2007;21(2):132-8.

18. Georgita C, Albu F, David V, Medvedovici A. Simultaneous assay of metformin and glibenclamide in human plasma based on extraction-less sample preparation procedure and LC/(APCI)MS. Journal of Chromatography B. 2007;854(1-2):211-8.

19. Zhang L, Tian Y, Zhang Z, Chen Y. Simultaneous determination of metformin and rosiglitazone in human plasma by liquid chromatography/tandem mass spectrometry with electrospray ionization: Application to a pharmacokinetic study. Journal of Chromatography B. 2007;854(1-2):91-8. 
20. Marques MA, Soares Ade S, Pinto OW, Barroso PT, Pinto DP, FerreiraFilho $\mathrm{M}$, et al. Simple and rapid method determination for metformin in human plasma using high performance liquid chromatography tandem mass spectrometry: Application to pharmacokinetic studies. Journal of Chromatography B. 2007;852(1-2):308-16.

21. Chen X, Gu Q, Qiu F, Zhong D. Rapid determination of metformin in human plasma by liquid chromatography-tandem mass spectrometry method. Journal of Chromatography B. 2004;802(2):377-81

22. Sengupta P, Bhaumik U, Ghosh A, Sarkar AK, Chatterjee B, Bose A, et al. LC-MS-MS development and validation for simultaneous quantitation of metformin, glimepiride and pioglitazone in human plasma and its application to a bioequivalence study. Chromatographia. 2009;69(11-12):1243-50.

23. Shah PA, Shrivastav PS. Ion-pair solid phase extraction for the simultaneous separation and quantitation of Metformin and Canagliflozin in human plasma by LC-MS/MS. Microchemical Journal. 2018;143:181-9.

24. US DHHS, FDA, CDER, CVM. Guidance for Industry: Bioanalytical Method Validation. U.S. Department of Health and Human Services, Food and Drug Administration, Center for Drug Evaluation and Research (CDER), Center for Veterinary Medicine (CVM), Rockville, MD, USA. 2018.

\section{PICTORIAL ABSTRACT}

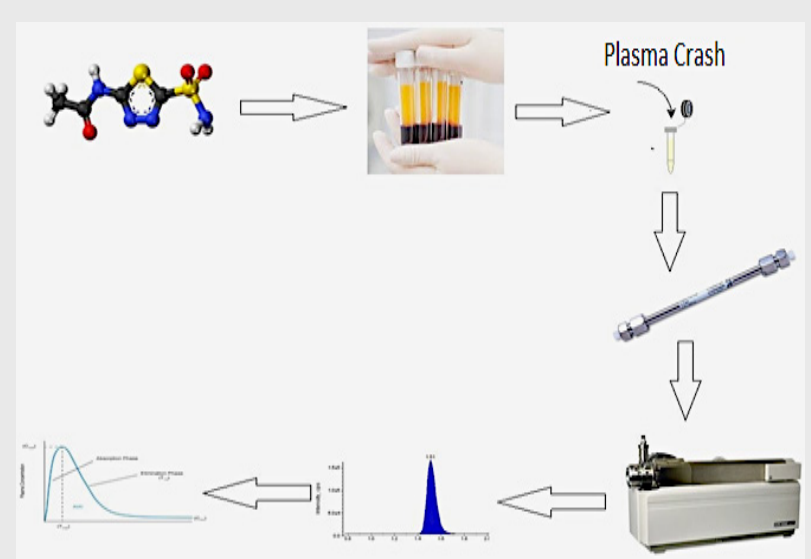

\section{About Authors}

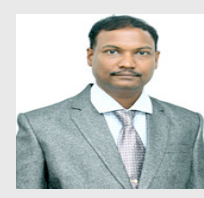

Dr. A. Lakshmana Rao is working as a Professor and Principal at V. V. Institute of Pharmaceutical Sciences, Gudlavalleru. He is having 19 years of Teaching, Research and Administrative experience. He guided 8 Ph.D. Scholars and 41 M.Pharm Candidates. He Received Noble Principal of the Year Award from Operant Pharmacy Federation and Principal of the Year Award from Association of Pharmacy Professionals. He conferred with Meritorious University Best Teacher Award from Jawaharlal Nehru Technological University Kakinada, Kakinada. He published 273 papers in various International and National Journals. He is Editor-in-Chief, Reviewer and Editorial Board Member for 104 reputed International and National journals. He organized 23 Seminars, Conferences and Workshops. He participated 85 Seminars, Conferences and Workshops. He is having memberships in 10 professional societies.

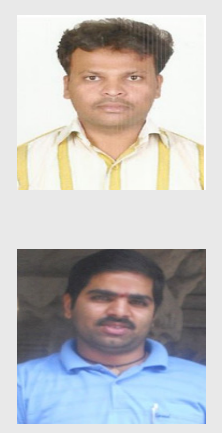

R. Muralikrishna is currently pursuing Ph.D in Faculty of Pharmaceutical Sciences, Krishna University, Machilipatnam, Andhra Pradesh, India. He is having 6 years of teaching experience.

Mr. A. Vinayendar, currently pursuing his Doctoral Degree from Rayalaseema University, Andhra Pradesh, India. Also, he is working as a Senior Bioanalytical Scientist at PCR Laboratories, Hyderabad, India. 


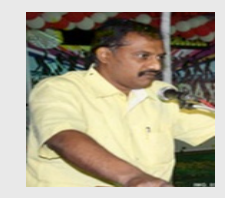

Dr. M.V. Basaveswara Rao is Professor at Department of Chemistry, Chairman, BOS, Chemistry and Pharmacy, Krishna University, Machilipatnam. He is Honorary Secretary, Andhra Pradesh Akademi of Sciences, Amaravati and Member, Executive Council, Krishna University. He is Former Member, Academic Council, IGNOU, New Delhi. He is Special Officer, Krishna University Dr. MRAR Campus, Nuzvid and Dean, Faculty of Sciences, Krishna University. He is Member of Academic Senate, Krishna University and Member, IQAC, Krishna University. He is Member of Planning and Monitoring Board, Krishna University.

Cite this article: Ramisetti M, Rao AL, Rao MVB, Adireddy V. Simultaneous Determination of Canagliflozin and Metformin in Human Plasma by LC-MS/MS Assay and its Application to a Human Pharmacokinetic Study. Indian $\mathrm{J}$ of Pharmaceutical Education and Research. 2019;53(3 Suppl 2):s364-s372. 